\title{
Questions and their responses in Tzeltal
}

\author{
Penelope Brown* \\ Max Planck Institute for Psycholinguistics, PB 310, NL 6500AH Nijmegen, The Netherlands
}

\section{A R T I C L E I N F O}

\section{Article history:}

Received 4 February 2010

Accepted 1 April 2010

\section{Keywords:}

Question

Answer

Conversation analysis

Tzeltal

Echo responses

\begin{abstract}
A B S T R A C T
This paper reports the results of a study of Tzeltal questions and their responses, based on a collection of 419 question/response sequences drawn from video recordings of 'maximally casual' naturally occurring face-to-face interactions in a Tzeltal (Mayan) community. I describe the lexical and grammatical resources for formulating content and polar questions in Tzeltal, the different kinds of social actions that questions can be used to perform and their relative frequency in the data, and the characteristic properties of responses to questions. This is part of a large-scale comparative study of questions in 10 different languages, and we find that Tzeltal is like most others in making much more use of polar than of content questions, and in the strong tendency for confirming answers to polar questions. Tzeltal is however unusual in three respects: in the comparatively minimal use of gaze to select next speaker, in the frequency with which answers take the form of repeats, and in the complete absence of visible-only responses (e.g., nods or headshakes). There are also some language-specific properties of question-answer sequences that reveal cultural shaping of sequencing in conversation.
\end{abstract}

(c) 2010 Elsevier B.V. All rights reserved.

\section{Introduction}

This paper - on how Tzeltal questions are formulated and how they are responded to in conversation - is a contribution to the large literature on questions, which have received considerable attention both in studies of face-to-face interaction and in linguistics, including to some extent in other Mayan languages. ${ }^{1}$ A major issue for interactors is the formulation and maintenance of common ground, shared understandings which are continually being updated through talk (Clark, 1996). Questions and responses to them are a crucial resource for achieving this. In Conversation Analysis, question-answer sequences are taken to be the paradigm case of an 'adjacency pair': a question makes relevant an answer, and whatever happens in that sequential location will be read in light of that expectation (Schegloff, 1968). In linguistics, the interrogative function is claimed to be a universal feature of languages (König and Siemund, 2007).

What is the scope of such generalizations? Do information questions have the same sorts of structures in radically different languages and cultures? Do they perform the same range of functions in talk? Is there a discernable preference structure to the forms that questions take, and to how answers are matched in form to questions? Are there language- and culture-specific uses of questions? The comparative project of which this study forms a part has attempted to address these issues by developing a method for creating a collection of question-and-responses drawn from videotapes of everyday natural conversation and a coding system suitable for comparative analysis. Our working definition of an information

\footnotetext{
* Present address: Max Planck Institute for Psycholinguistics, PB 310, 6500 AH, Nijmegen, The Netherlands. Tel.: +31 243521441 ; fax: +31 24 3521300. E-mail address: pbrown@mpi.nl.

1 Most of this work is on linguistic form rather than usage, and mostly on Yucatec Maya (e.g., Bohnemeyer, 2002; Bricker, 1979; Tonhauser, 2002). See also Brody (2003) on Tojolobal and Aissen (1996) on Tzotzil, the Mayan language mostly closed related to Tzeltal. Brief discussions of Tzeltal question/response forms can be found in some grammars (e.g., Monod-Bequelin, 1997:116-18).
} 
Table 1

Distribution of $\mathrm{WH}$, polar, and alternative questions.

\begin{tabular}{lc}
\hline & Frequency \\
\hline Polar & $230(74 \%)$ \\
Content (WH) & $75(24 \%)$ \\
Alternative & $4(1 \%)$ \\
Total & 309 \\
\hline
\end{tabular}

question (IQ) was this: to be included in the collection, an utterance had to either be (i) formally marked as interrogative (via morphosyntactic marking or intonation) or (ii) be information-seeking, a functional definition in terms of making the provision of information - including confirmation/disconfirmation - the relevant next action of the addressee.

The data presented here come from a Tzeltal collection of 419 question-response sequences drawn from video recordings of 'maximally casual' naturally occurring face-to-face interactions in the Tzeltal (Mayan) community of Tenejapa, in southeastern Mexico. ${ }^{2}$ The corpus includes conversations among household members during meals or chores, or just sitting around relaxing, and conversations with visitors in a variety of households as well as chance encounters on the road or other public space. The collection is based on samples totalling about $2.5 \mathrm{~h}$ taken from 12 Tzeltal conversations with a total of 20 different participants, of both sexes, whose ages ranged from the 20 s to the 70 s. $^{3}$ The video data were transcribed in the field with the help of native speakers, digitized and annotated in the video annotation program Elan; questions were coded for formal linguistic properties, for the types of action they performed, and for the nature of the responses. Analyses were run on functional information questions (henceforth IQs), so rhetorical questions (which comprised $22 \%$ of the Tzeltal data) were omitted, as they have quite different sequential implications. ${ }^{4}$ This means that the total of 419 coded questions was reduced to 326 functional questions; we also set aside all through-produced 'multi-questions' (two or more questions produced in a single turn of talk), leaving a total of 309 questions on which the analyses presented here are based. (See the introduction to this special issue for details of the sampling and coding procedures.)

In what follows, I first describe the Tzeltal lexical and grammatical resources for formulating questions and indicate their distribution in the data. Section 3 addresses the range of actions speakers perform with questions in conversation. In section 4 I ask to what extent, and how, the responses to questions are 'fitted' to the form of the questions. Section 5 offers some conclusions about what is language-specific in the Tzeltal data and what support for universal tendencies we find.

\section{Lexico-grammatical resources for questioning}

Tzeltal is a VOS, head-marking, mildly polysynthetic language, with obligatory ergative/absolutive marking on the verb which cross-references the core participants; ergatives also mark possessors on nouns. A rich system of evidential and discourse particles mark access to information and epistemic stance. There is free ellipsis of arguments understandable in the context; many utterances consist of a verb alone. These properties, as we shall see, provide structural constraints that affect the forms of questions and responses in Tzeltal conversation.

The information structure of the questions in the dataset falls neatly into three types, polar (Yes/No) questions which ask for a proposition to be affirmed or denied, content (or WH) questions which request a specific piece of information to be supplied, and alternative questions which list two (or more) alternatives and request adjudication between them (e.g., 'Is it X or is it Y?'). Their respective distributions in the data are provided in Table 1 . As in other languages, content question forms and polar question forms are grammatically distinct in Tzeltal; alternative questions were a marginal phenomenon in the data under consideration.

Tzeltal provides a variety of formal ways to mark illocutionary force. For this project marking included language-specific lexical-morphosyntactic or prosodic (intonation or otherwise) properties (Stivers and Enfield, this issue). Utterances thus marked of course do not always function as information questions; there are many different functions expressable by utterances that are grammatically interrogative (Schegloff, 1984). In the Tzeltal data, lexical/morphological marking characterized $54 \%$ of the questions. $16 \%$ were marked with intonation alone (a rising final contour); the rest were formally unmarked (see Table 2).

\footnotetext{
${ }^{2}$ Tenejapa is a rural community with a population of about 35,000 Mayan corn farmers living a largely subsistence lifestyle in a ruggedly mountainous area of highland Chiapas. Until recently there were no all-weather roads into Tenejapa, so many people are still relatively isolated from the surrounding Mexican national culture and are effectively monolingual in Tzeltal. Most Tenejapans under the age of about 35 are partially bilingual in Spanish, and others in the neighboring language Tzotzil. But Tzeltal remains the primary language of the community and is universally spoken in the home. In this relatively homogeneous community the main bases for social differentiation are gender and age; these provide the sole bases for sociolinguistic variation in the data discussed here.

${ }^{3}$ These are the samples for which the coding was refined and from which the quantitative data reported here is derived. I initially coded samples from another nine Tzeltal conversations; examples here are drawn from the full set of data (the data source and the location of the question in the video are indicated in square brackets at the beginning of examples). The videotapes were collected during regular field trips from 1980 through 2005.

${ }^{4}$ Rhetorical questions function not to request information but to express an attitude or stance, and they solicit not answers but agreement with the stance taken. Tzeltal rhetorical questions have features in common with the 'reverse polarity questions' (RPQs) described for English (Koshik, 2005), but in Tzeltal they are conventional and frequent in everyday discourse. Some of their interactional functions are described in Brown (1995).
} 
Table 2

Lexical/morphological marking of questions.

\begin{tabular}{|c|c|c|c|c|}
\hline Type of question & Lexically/morphologically marked & Marked by intonation only & Unmarked & Total \\
\hline Polar & 87 & 50 & 93 & 230 \\
\hline Content (WH) & 75 & 0 & 0 & 75 \\
\hline Alternative & 4 & 0 & 0 & 4 \\
\hline Total & $166(54 \%)$ & $50(16 \%)$ & $93(30 \%)$ & 309 \\
\hline
\end{tabular}

Table 3

Content question forms in Tzeltal.

\begin{tabular}{|c|c|c|c|}
\hline & Tzeltal form & $\begin{array}{l}\text { Tzeltal examples } \\
\text { (mostly constructed) }\end{array}$ & Gloss \\
\hline What & bi/bin/binti & bi(nti) ya a'pas? & 'What are you doing?' \\
\hline \multirow[t]{2}{*}{ Where } & ba/banti & ba(nti) ay te kaxae? & 'Where is the box?' \\
\hline & & banti a'lijk tal? & 'Where did he come from?' \\
\hline Who & mach'a & mach'a ya xkajin? & 'Who is singing?' \\
\hline Whose & mach'a y-u'un & mach'a yu'un te alale? & 'Whose child is this?' \\
\hline How much & jay-eb & jayeb stojol? & 'How much does it cost?' [lit.: 'How much (is) its price?'] \\
\hline How many & & jayeb ja'wil a'wich'oj? & 'How old are you?' [lit.: 'How many years have you received?'] \\
\hline When & bi'ora & bi'ora sujtik tal? & 'When did they come back?' [lit.: 'What hour/time. ..?'] \\
\hline What time & & jayeb ora? & 'When.' [lit: 'How many hours.'] \\
\hline How & bit'il [< bin ut'il] & bit'il a' laj? & 'How did he die?'[lit.: 'In what manner/by what cause...?'] \\
\hline Why & bi $y$-u'un & bi yu'un ya x'ok'at? & 'Why are you crying?' [lit.: 'What (is) its-cause/reason. ..?'] \\
\hline What use, what for & bi s-tuk & bi stuk ku'un? & 'What use is it to me?' [lit: 'What (is) its-use mine?'] \\
\hline For what purpose & bi s-wenta-il & bi swentail ya'k'opon te xune? & $\begin{array}{l}\text { 'For what purpose do you want to talk to Xun?' [lit.: } \\
\text { 'What (is) its-reason/purpose... ?'] }\end{array}$ \\
\hline What time of day & bi (y-i)lel k'inal & $\begin{array}{l}\text { bi yilel k'inal a' jelawik i? } \\
\text { [xantmex6B 2:07:] }\end{array}$ & $\begin{array}{l}\text { 'What time of day did they pass by?' [lit: 'What (was) } \\
\text { its-appearance, the land/day ...?'] }\end{array}$ \\
\hline How far & bi s-najt-il? & bi snajtil $x a$ 'wil te'ye? & 'How far is that from you?' [lit.: 'What is its distance...?'] \\
\hline
\end{tabular}

The total of 309 is the total on which most of the calculations presented here was based; it excludes 17 through-produced multi-questions. (Slight variations from the 309 in some totals reported below reflect cases where questions were uncodable for the property at issue.)

\subsection{Content (WH-)questions}

The conventional Tzeltal words and expressions for constructing 'constituent interrogatives' (König and Siemund, 2007) are listed in Table 3. Three of these are monomorphemic ('what', 'where', 'who'), and one is a single morpheme jay- plus an obligatory numeral classifier suffix ('how much, how many'); this is the only one that can be inflected for person (as in example 3 below). Other WH expressions are constructed with bi or bin, short forms of binti 'what' - for example, WHEN = ' (at) what time', WHY = '(for) what reason', HOW = '(in) what way', etc. When functioning as WH-question words ${ }^{5}$ these occur in first position in the clause, and in their full form (binti, banti, mach'a) they can occur alone, as the only word(s) in an utterance. Those constructed with bi can have a particle intervening between the $b i$ and the rest of the WH expression (as in example 4 below); mach'a 'who' can also take the subjunctive suffix $-u k(\mathrm{cf} .<6>$ ). These are the main resources speakers can draw on to formulate $\mathrm{WH}$ questions.

Some examples of actual usage follow, drawn from the conversational data. ${ }^{6}$ Many are straightforward information requests:

$<1>\quad$ [xunsen 42:21:, talking about the reported speech of MS]

$$
\begin{aligned}
& \text { MS: ^binti laj xon ek tz'in? } \\
& \text { what QUOT I.said too PT } \\
& \text { 'What did she say I said then?' }
\end{aligned}
$$

\footnotetext{
${ }^{5}$ The content- $\mathrm{Q}$ forms also function as relative pronouns, as in 'I don't know who came.'

${ }^{6}$ I use a practical orthography for Tzeltal, where $\mathrm{j}=[\mathrm{h}]$ and ' indicates a glottal stop or glottalized consonant. The following abbreviations are used in interlinear morpheme glosses: 1/2/3 - first/second/third person; E - ergative, possessor; A - absolutive; ACS - achieved change of state particle; ASP neutral aspect; CAUS - causative; CL - numeral classifier; CLI - clause-final clitic; CMP - completive aspect; CNT - continuative; DEIC - deictic; DET definite determiner; DIM - diminutive; DIR - directional; DIS - dispositional stative; DIT - ditransitive; EXCL - exclamatory particle; EXIST - existential predicate; HON - honorific prefix; IMP - imperative; ICP - incompletive aspect; INCH - inchoative; NEG - negative particle; NOM - nominalizer; PERF perfect aspect; 1 PLI - 1st person inclusive plural; 1PLE - 1st person exclusive plural; PL - 2nd/3rd person plural; PREP - generic preposition; PT - discourse/ evidential particle; Q - polar question particle bal; QUOT - quotative; RELN - relational noun; RES - resultative; SUBJ - subjunctive; TAG - sentence-final $b i$; WH - Wh-question particle, ! - proposition affirmation ('it is the case that'). ${ }^{\wedge}$ indicates shift to high pitch, [ marks onset of overlapping speech, and indicates final trailing off pitch contour.
} 
[xansen 37:43:, talking about gossip spreading]

An: banti $a^{\prime} w-a^{\prime} y-o j-0 \quad t z^{\prime}$ in $=e$ ?

where 2E-hear-PERF-3A PT=CLI

'So where did you hear it?'

[T012036 bot50 14:44:; $\mathrm{M}$ is asking her visitor A how many are in his (natal) family]
$\mathrm{M}: \quad$ jayeb-ex nix $t z^{\prime}$ in $\left[\mathrm{ch}^{\prime} i\right.$ ?
how.many-2A PT PT PT
'So how many are you?'

$<4 \quad$ [chelap 30:28:, C has come visiting, and is discussing the sale of a kitten]

C: bi nax ut'il ya ' $w$-ak'-0 xkal.

what PT way ICP 2E-give-3A PT

'For what (lit: 'in just what way') will you give [sell/trade] it?'

In addition to forms for content questions, there is a generic other-repair-initiation form jai, which has no literal meaning and is etymologically related to no other word. Jai indicates non-hearing or non-comprehension of the prior utterance; it is roughly equivalent to English 'What (did you say)?' or 'Huh?'(see Schegloff et al., 1977; Drew, 1997), prompting the prior speaker to repeat it, as in:

$<5>$

[T019028 pak'elv7 15:34:]

$\mathrm{P}$ : pero $a^{\prime}-k^{\prime}$ inal $=e$ tey to nix ay-0.

but 2E-land=CLI there still PT EXIST-3A

'But you still have your land there?'

A: jai?

'What (did you say)?'

P: tey to nix ay-0 [tz'i '- $k^{\prime}$ inal.

there still PT EXIST-3A PT 2E-land

'You still have your land there.'

A:

[tey pero (.) ya j-chon-0.
there but 1E-sell-3A
'(It's) there but I'm selling it.'

Other WH forms can be used to initiate repair by specifying precisely which piece of information needs to be supplied, as in $<6>$ :

$<6>\quad$ [T019008 pak'elv7 11:32:, P is asking about his visitor A's land]

P: $\quad$ ma ay-uk to $a^{\prime}$-k'inal tey $a$.

NEG EXIST-SUBJ still 2E-land there DEIC

'Don't you still have land there?'

(.8)

A: $\quad$ ma s-mak-oj-ik ye $t z^{\prime} i$.

NEG 3E-block-PERF-3Epl PT PT

'So they haven't taken it (away) then.' [-> They have!] NEW INFORMATION

(.8)

$->\mathrm{P}$ : mach'a-uk?

who-SUBJ

'Who might it be [who took it away]?'

(.4)

A: $\quad$ ja' nix s-mak-oj-ik tz'i x-nich'an anima j-mamal

! PT 3E-block-PERF-PL PT 3E-son deceased HON-old.man

j-tajun ya -'w-il.

1E-uncle ICP 2E-see

'It's the son of my deceased elderly uncle (who) has taken it, you see.' 
Table 4

Frequency of different types of WH-question.

\begin{tabular}{lcc}
\hline & Frequency & Percent \\
\hline Person (Who?) & 10 & 13 \\
Thing (What?) & 11 & 15 \\
Place (Where?) & 15 & 20 \\
Time (When?) & 3 & 4 \\
Reason (Why?) & 5 & 7 \\
Manner (How?) & 4 & 5 \\
Amount (How much?) & 3 & 4 \\
jai 'what (did you say)?/huh?' & 24 & 32 \\
Total & 75 & \\
\hline
\end{tabular}

The different types of content question were not equally frequent in the data, as can be seen in Table 4, which groups the questions by function (by which bit of information they prompt for) rather than purely by form. Nearly half of the 75 WH-questions (48\%) were functionally either Who-questions (requesting identification of a person as the response), Whatquestions (requesting information about a thing or a situation), or Where-questions (requesting a place). A third of the content questions consisted of jai 'what?', the dedicated hearing/understanding repair initiator. Content question forms also occur in a high proportion of rhetorical questions, which were not counted in any of the calculations reported here.

Content question forms are always first in the clause. A very small number occur in the data as one-word utterances (the question form alone), as in $<6>$ above.

\subsection{Polar questions}

The Tzeltal clause has three distinct positions or 'slots' where one or more of a set of about 10 evidential and sentencemodifying particles may be inserted: clause initial, second slot, and clause final. For polar questions Tzeltal has two kinds of dedicated lexical markers, distinguished by which slot they occur in the clause: the interrogative particle bal (second slot), and the turn-final question-marking (or, loosely, 'tag') particle bi (final slot). Intonation alone can also mark a sentence as interrogative. ${ }^{7}$ Utterances marked only with a dubitative particle (in first, second, and/or sentence-final slot) may also function as questions, as can unmarked 'declarative' questions. We will consider each of these in turn.

\subsubsection{Polar questions marked with bal}

The second-position set of particles includes a quotative particle and various emphatic and dubitative evidential particles, in addition to the canonical polar question particle bal. The second-slot position means that the particle falls between the aspect marking or preposed adverb and the rest of the inflected verb, in which case it can never be utterance final (the rest of the inflected verb is obligatorily present), as in example $<7>$ :

$<7>\quad$ [tajun 20:58:S]

ya bal $a^{\prime}-k^{\prime} u x-0$ ?

ICP Q 2E-eat.crunchy.things-3A

'Will you eat (it)?' [offering ear of young corn]

But in stative clauses and others not beginning with a verb, the particle falls after the stative predicate or adverb, in which case it can be utterance-final, as in 8 :

$<8>\quad$ [T035034 xunxtin7A 13:45:, T is talking about husband's meeting]

$\mathrm{T}: \quad j a$ ' jich bwen $\quad$ sab lok'-em-0 bel.
! thus thoroughly morning exit-PERF-3A DIRawaywards
'It was thus really early morning (when) they left.'
$\mathrm{X}: \quad$ sab $\quad$ ba:l.
EXCL morning Q
'Ai, early morning?
[sab.
'Early morning.'

\footnotetext{
${ }^{7}$ A rising final intonation contour characterizes many questions in the collection, but many others carry a falling contour. There is another use for rising intonation-a trailing-off utterance-final contour frequently employed in Tzeltal discourse for indicating a helpless or fatalistic stance. A proper analysis of Tzeltal intonation and its conversational functions remains to be done.
} 
Negative questions with the negative particle $m a$ are formed in the same way, with bal falling immediately after the negative marker, as in the first line of $<9>$, or after other second-slot particles, as in line 2 of $<9>$ :

$<9>\quad$ [bot49 00:12:, B has been telling about the first time airplanes came over the community]
A: ma bal la ' $w$-il $i$,
NEG Q CMP 2E-see DEIC,
$m a$ to bal la ' $w$-il a'[-tukel $0 \quad y$-al-0 tal xulem tak'in [li'=e.
NEG PT Q CMP 2E-see 2E-self CMP 3E-fall coming airplane here=CLI
'You didn't see this, you hadn't yet yourself seen airplane(s) coming down here?'
B:
[ma to.
'Not yet.'
[tzail-on to a.
'I was still young.'

The particle bal occurs in 34 (15\%) of polar questions in the data; 20 of these are straightforward information requests. But sometimes a question marked with bal occurs in response to a piece of newly proffered information, requesting confirmation of it:

$<10>\quad$ [chanit 18:38; $\mathrm{C}$ is host, $\mathrm{A}$ is visitor, getting ready to close down conversation]

C: $\quad$ paxyal ta ba k'alal ya x'-ala ben-at xan ya'[tik ch'e. travel PREP where all.the.way ICP ASP-DIM walk-2A again today PT '(You'll be) travelling around to wherever you're walking to now, eh.'

A: [ya $x$-ba k-a'y xan julbal jo'tik li' ta alan bel $i=$ ICP ASP-go 1E-feel again visiting 1PLE here PREP downhil DIRgoing DEIC 'We'll go visiting again here away downhill.'

$->\mathrm{C}: \quad=y a k$ bal $-=$ yes Q 'Yes?' [i.e., will you?]

A: $=y a k$. 'Yes.'

A distinct set of particles falls not in second position but clause-finally. Again, this is a large set of particles, one of which has a clear question-marking role. Others are simply dubitative or emphatic, but may also be used to construct questions.

\subsubsection{Turn-final question-marking particles ("tags") with bi}

In contrast to content question words and bal, which pre-figure the utterance under construction as a candidate question, question-markers which go in the sentence-final slot indicate the illocutionary force only as the utterance ends, allowing speakers to re-formulate their utterance as a question on-line, in response, for example, to early feedback (Enfield et al., 2006). The best candidate in Tzeltal for a turn-final-question marker is the particle bi, possibly derived historically from the Wh-word $b i(n t i)$ 'what'. Bi hedges the speaker's commitment to the claim made by the utterance, and in many cases seems to behave like tags in English. In the current study, I counted as tags both final $b i$ and the further evidentially hedged $b i \mathrm{ma}(k)$ ( $m a$ indicates the proposition is not first-hand knowledge for the speaker, but is inferred). Tags with bi comprised $23 \%$ of polar questions in the data; these were primarily used to solicit confirmation from the addressee:

$<11>\quad$ [xmalosil6C_04 7:39:]

L: jo', la '-k'ok-ix tz'i a'w-ala ja'as-ik bi.

huh CMP 2E-pluck-ACS PT 2E-DIM ja'as-PL TAG

'Huh, you picked your sapote eh?' [marks speaker's inference and request for confirmation, as she looks at a large bag of sapote fruits on addressee's patio]

M: $\quad$ la=e

$\mathrm{CMP}=\mathrm{CLI}$

'(I) did.'

In the conversational data, $b i$ is quite likely to occur as a response to information just provided, asking for confirmation of it.

$<12>\quad$ [chanit 12:06:, A is visiting C, and reporting news from a meeting he (A) attended on the previous day]
A:
jich bayel j-me'tik
j-tatik
la $y$-a'y (.4)

thus many HON-'mothers' HON-'fathers' CMP 3E-hear 


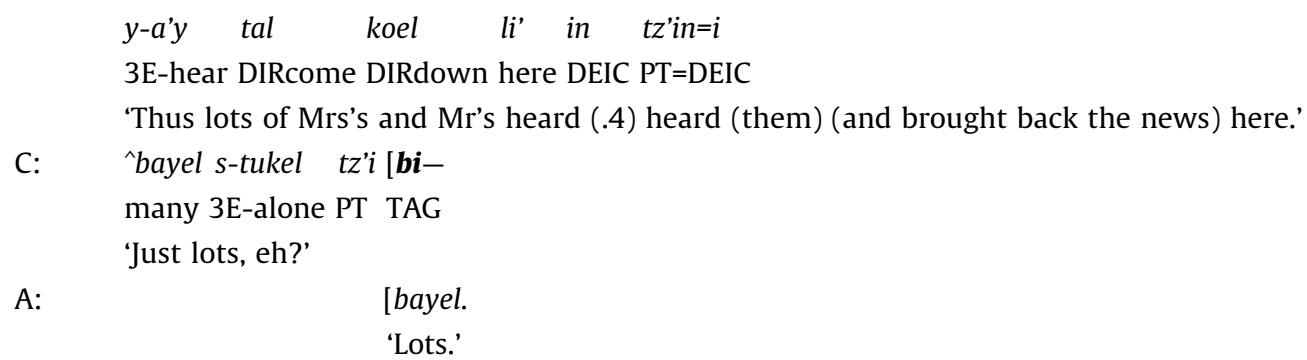

A problem for the analyst (but not apparently for participants) arises when there is an epistemic mismatch, with the participant who knows the information making assertions about it marked with $b i$ (this is also true to a lesser extent for bal). That is, a $b i$-marked utterance is not always asking the addressee to confirm something (s)he knows more about than the current speaker; indeed, you can find two bi's in successive turns, in a confirmatory repeat sequence as in $<13>$, where ao's utterance ending with bi marks his lack of direct knowledge and requests confirmation, while t's response marks his own experience (that's what I heard') with bi as a hedge, perhaps on correctly remembering what he'd heard:

$<13>\quad$ [bot v49p28 39:00; $t$ is the knowledgeable one]

\begin{tabular}{|c|c|}
\hline ao: & ja'w-a'y bit'il ay-0 tz'in ch'i j-tatik. \\
\hline & ! 2E-hear how EXIST-3A PT PT HON-'sir' \\
\hline & 'So I see how it is then, sir.' \\
\hline $\mathrm{t}:$ & jich mene. \\
\hline & thus that \\
\hline & 'That's how it is.' \\
\hline ao: & ja' nax jich $a^{\prime} w$-a'y-oj \\
\hline & ! PT thus 2E-hear-PERF PT TAG \\
\hline & 'That's just what you heard then eh?' \\
\hline $\mathrm{t}:$ & ja' jich k-a'y-oj \\
\hline & ! thus 1E-hear-PERF too TAG \\
\hline & 'That's just what I heard eh.' \\
\hline 10: & ja' kati. \\
\hline & ! PT \\
\hline & 'That's so eh!' \\
\hline t: & jm. \\
\hline
\end{tabular}

Thus even when the speaker is the expert on the topic, he may still mark his utterance with $b i$, soliciting agreement:

$<14>\quad$ [T012011 bot50 5:37:, B is a curer diagnosing an illness by feeling patient's pulse, A is responsible for the patient and therefore will have to pay for any candles used in the ceremony]

B: $\quad$ ji pero muk' kantela ya s-k'an-0 tz'i bi.

EXCL but big candle ICP 3E-want-3A PT TAG

'Ii, but it [the curing ceremony] needs big candles eh.' (i.e., I reckon, do you agree?)

A: muk' kantela s-k'an.

big candle ICP 3E-want

'It needs big candles.'

B: $\quad$ muk' na'ax. melel $y$-ora-il $\quad y a-' w$-a'y.

big PT truly 3E-time-NOM ICP 2E-see

'(It needs) big ones. (Because) really it's time for it [the ceremony] you see.'

A: aj wa'y $y a^{-}{ }^{\prime} w-a^{\prime} y$.

ah 2E-see ICP 2E-see

'Ah I see.' 
Marking with bi can occur when the speaker knows the addressee does not actually know the answer, when asking for confirmation of something that is a possible implication of what has just been said:

$<15>\quad$ [AMTantosil 28:41:, talking about the response of people at a meeting in town to news about things the governor will provide funds for; $A$ is the knowledgeable one telling about the meeting]
A: ej ak'ol ni me y-o'tan-ik yael tz'i bi-
eh happy PT if 3E-heart-PL apparently PT TAG
C: ak'ol nax.
happy PT
'Just happy.'
A: $\quad a k$ 'ol.
'Happy.'

Finally, questions are occasionally double marked with both the second-slot particle bal and the tag-question marker $b i$ :

$<16>\quad$ [chanit 8:09:, A has just told $\mathrm{C}$ that the governor provided financial aid for roads, house building materials, etc.]
C:
bal ya
$x$-meltzaj-0 s-na-ik
a tz'i bi?
! $\mathrm{Q}$
ICP
ASP-fix-3A 3E-house-PL IA PT TAG

'Do they fix their houses then eh?' [i.e., with the aid money]

(.5)
A: ma laj la s-lek-u-tes-ik, tey me ay-0 laj
NEG QUOT CMP 3E-good-INCH-CAUS-PL there if EXIST-3A QUOT
museo $\quad y$-u'un-ik.=
museum 3E-RELN-PL
'They didn't fix them up, they say, (it's for) their museum they say.' [Casa de Cultura]
C: $\quad=a:: j$
'Ah.'

This double marking occurs with Tzeltal WH words as well, a phenomenon that has also been found in Japanese (Hayashi, this volume):

$<17>\quad$ [bot1:09:]
jich baxe' jayeb k'al a jalaj-0 tz'i bi?
thus who.knows how.many day CMP last-3A PT TAG
'So who knows how many days did they stay then eh?'

The fact that bi can occur in utterances expressing propositions that are clearly within the speaker's own knowledge domain, and in combination with a genuine interrogative marker (bal or a WH-word) indicates that bi is not strictly a marker of interrogative sentence type (König and Siemund, 2007). ${ }^{8}$ Nor is bi usually appended to a declaratively phrased utterance to shift its illocutionary force at the last minute; rather it tends to be intonationally integrated into a single sentence contour. I conclude that bi marks lack of epistemic commitment more generally, but an utterance marked with bi does act as the first part of an adjacency pair, creating the expectation that it will be followed by an answer confirming or disconfirming the proposition expressed if possible, or concurring in the doubt.

\subsubsection{Dubitative marking of questions}

Finally, we need to consider the set of dubitative particles which, by virtue of indicating a speaker's doubt or hesitation with regard to the truth of his/her utterance, can be used to construct utterances that are functionally equivalent to questions. Dubitative particles are not 'dedicated to' the function of doing IQs but often are part of functional IQs, sometimes in combination with interrogative markers. 25\% of IQs in the data set were dubitatively marked. Examples of utterances with the particles that most frequently appear follow. None of these particles, regardless of whether they occur in first, second, or last position in the clause, can ever occur alone.

\footnotetext{
${ }^{8}$ Indeed, König and Siemund (2007:301) claim that, cross-linguistically, interrogative tags do not occur in constituent interrogatives.
} 
2.2.3.1. Initial position mak. Mak is a suppositional particle indicating that the speaker does not know the truth of the proposition expressed but supposes it to be true, making relevant in the next turn the addressee's opinion/knowledge about it:

$<18>\quad$ [chanit 13:19:, talking about which of C's elderly relatives are still alive, here A is querying the identity of a 'sir', the generic honorific for male elders]
A: $\quad y a n$ tz'i (.) j-tatik $a^{\prime} w$-u'un=e ma ja'-uk-
other PT HON-'sir' 2E-RELN=CLI NEG !-SUBJ
'as for your 'sir', isn't it-'
C: $\quad$ [[coughs]] (1.0) jai?
'What?'
A: mak ja' a'-bankil, a'-bankil niwan.
PT ! 2E-elder.brother 2E-elder.brother PT
'(or) maybe it's your elder brother, it's your elder brother perhaps.'

Sentence-initial mak + a WH word indicates that the speaker does not expect the addressee to know the answer either:

$<19>\quad$ [xunsen:aud. $t$ is a visitor; the 'she' referred to is her addressee's sister]

$t$; ah: mak bi yu'un i $0 \quad$ lijk-0 s-k'ajk'al a k-a'y tz'in.

ah PT why DEIC CMP begin-3A 3E-anger CMP 1E-hear PT

'Ah, why then might she have begun to get angry (at me) then?'

2.2.3.2. Second position particles. A different set of particles is restricted to the second position slot in the clause, including the quotative laj and a number of dubitatives including niwan/wan 'perhaps', mati 'maybe', me as a hedge. These indicate different levels of speaker uncertainty and epistemic commitment and do not necessarily prompt for an answer response, unless the proposition expressed is in the addressee's knowledge domain, as in:

$<20>\quad$ [chanit 13:13:, the person whom A is asking about ('muk'ul jtatik') is C's father]

A: $\quad k u x u l-0$ to wan s-tukel $i()$.$j -muk'ul j-tatik i?$
alive-3A still PT 3E-self this HON-big HON-'sir' DEIC

'Big 'sir' [i.e., your father] is perhaps still alive?'

$(.4)$

C: $\quad$ kuxul-0.

alive-3A

'He's alive.'

Amongst the second-position particles is the quotative particle laj, which is used to claim that the information - or the speech act - expressed has a source other than the speaker. Laj can be used in questions to indicate that the question is made on behalf of a third party who is responsible for its illocutionary force:

$<21>\quad$ [Miktujk6A 5:23:]

ya laj bal $x$-we'-at yu' ma $0 \quad$ a'tej-at=e?

ICP QUOT Q ASP-eat-2A because NEG CMP work-2A=CLI

'Are you going to eat now [someone says], because you haven't worked (yet)?'

2.2.3.3. Sentence-final mak. There is a distinct particle mak (often reduced to $\mathrm{ma}$ ) restricted to sentence-final position. This is often best translated as 'I guess, I suppose'; it does not presume the addressee knows the answer but prompts for his/her view, knowledge, or supposition.

$<22>\quad$ [T006003 xunsen 41:09:, MS is a visitor who has come asking for medicines from a local nurse. The nurse isn't home; her sister $\mathrm{Xu}$ is the interlocutor]

MS: $j a^{\prime}$ to tz'is-le-be-0 tal koel $i$ mak.

! still PT 3E-look.for-DIT-3A DIRcome DIRdown DEIC PT 


\section{$\mathrm{Xu}: \quad j a^{\prime}$ to $t z^{\prime} i x-y-i c h^{\prime} \quad l e-e l=e \quad$ mak. \\ ! still PT ASP-3E-receive search.for-NOM=CLI PT \\ 'She still has to fetch them I suppose.'}

A combination of dubitative and interrogative particles may spell out the options in an alternative question, as in $<23>$ :

$<23>\quad$ [chanit 15:48:, $C$ is asking whether A (his visitor) or A's ex-wife have their children]
C: $\quad$ jal tz'i alal-etik $i-\quad y$-ik'-tikla-yej ya'tik tz'i mak=
but PT child-PL DEIC 3E-take-CNT-PERF now PT PT
'But the kids - she took them away then I guess,
$=a^{\prime} w$-ik'-oj-la bal.
2E-take-PERF-CNT Q
'[or] have you got them?'
A: $\quad j o^{\prime}$ o $y$-ik'-tikla.
no 3E-take-CNT
'No, she took them.'

In sum, dubitative particles, like dedicated interrogative particles, frame the utterance with illocutionary force that prompts the responder to supply missing information.

\subsubsection{Intonational marking of polar questions}

Like dubitative particles, final rising intonation may indicate epistemic uncertainty and thereby turn a statement into a question requesting new (not previously introduced) information:

[yixxanto_04v6D 1:15:]

aj, li' ay-0 i j-wix-itak i?

ah here EXIST-3A DEIC 1E-elder.sister-PL DEIC

'Ah, my elder-sisters are here [in majosik']?'

In the data, $22 \%$ of declarative questions were marked only intonationally. But final rising intonation is no guarantee that an utterance is intended as a question; there are other motivations for utterance-final rising intonation (see footnote 7). Final rising question-marking intonation does reliably occur on the other-repair initiator jai when it is used to request that the addressee repeat what he just said (equivalent to 'what did you say?'), distinguishing it from exclamatory jai (jai! meaning 'what you just said surprises me'). Intonation is often the only marker of question-hood when a participant is asking for confirmation of what was just said during an extended telling, as in the third turn of $<25>$ :

$<25>\quad$ [bot49 1:09:, B has been telling his visitor A a story about what happened in Tenejapa during the Villa/ Carranza wars long ago]

A: jich baxe' jayeb k'al a jalaj-0 tz'i bi?

thus who.knows how.many day CMP last-3A PT TAG

'So who knows how many days they [soldiers] stayed eh?'

(.4)

B: ej ay-0 k'aal tatil.

eh EXIST-3A day 'sonny'

'Eh there were days, sonny.' [i.e., lots of days]

(.3)

$->\mathrm{A}: \quad$ ay- $0 \quad$ k'aal? =

EXIST-3A day

'There were days?'

B: $\quad=a y-0$ laj k'aal.

EXIST-3A QUOT day

'There were days, they say.' 


\subsubsection{Unmarked 'declarative' questions}

It is perfectly possible in Tzeltal to have no overt marker of questioning illocutionary force at all; participants can often infer illocutionary force from the content of a declarative sentence in its sequential context in combination with their knowledge about who knows what. Indeed, $40 \%$ of the yes/no questions in the data set were entirely unmarked in any overt way. Often, but not necessarily, these were statements about B-events (Labov and Fanshel, 1977), things the addressee can be supposed to know more about than the speaker of the question, as in $<26>$ :

$<26>\quad$ [chanit 10:14:]

-> A: jich ma'yuk a' ba-at kati woje ek tz'in [ch'i. thus not/none CMP go-2A PT yesterday too PT PT 'Thus you didn't go at all yesterday [to the meeting].'

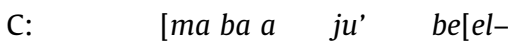
NEG CMP be.able go-NOM 'I wasn't up to going.'

A:

[ma a' ju:'.
NEG CMP be.able
'Not up to it.'

These declaratively phrased utterances are primarily used in offering an inference, a candidate interpretation, or a request for clarification (this is what you meant?)

\section{The range of social actions speakers perform with questions}

As we have seen, Tzeltal provides ample resources for formulating interrogatives and other questions that prompt for an answer response. What kinds of actions do utterances formulated using these resources actually perform in conversations? As Schegloff (1996) has observed, interrogative marking bears only an indirect relationship to conversational usage. Four major functions of questions can be identified in the Tzeltal conversation data:

(1) requesting new (not previously supplied) information (see extracts $1-4,9,16,20,23$, for some clear examples)

(2) requesting confirmation of propositions or claims that have already been introduced (see extracts 5-6, 8, 10, 12)

(3) requesting that the immediately prior utterance be repaired, because it was not heard, or was unclear, or was surprising or unbelievable (see extracts 5-6 above)

(4) assessments making relevant an agreement

Assessments are frequent actions in the data set, but are primarily achieved by formulating a question rhetorically (and therefore not considered here).

Other types of actions performed by questions identified in conversation analytic work on English (e.g., suggesting, requesting, offering) occur in the Tzeltal data, but - in comparison with the actions of requesting information and confirmation - were relatively infrequent. For example, $<27>$ is a request (see also example $<37>$ below; see $<7>$ and $<36>$ for offers).

$<27>\quad$ [T030010 chelapv5 4:06:; C is a visitor, asking to borrow X's plot of land again next year]

$\mathrm{C}: \quad a y-0$ to bal ba $y a$ 'x'-ala ' $w$-obolta-be- $n$ ta $y$-ala majan-el EXIST-0 still Q where ICP ASP-DIM 2E-help-DIT-1A PREP 3E-DIM borrow-NOM 'Will you just help us by letting us borrow it [land] again

s-k'an (1.1) x-k'ax-0 bel ja'wil k-an[tzil-

3E-want ASP-pass-3A DIRgo year 1E-girl

when the next year comes, my girl?'

$\mathrm{X}$ : [^ya to wan a'-majan-0 xan ek tz'in.

ICP still PT 2E-borrow-3A again too PT

'You perhaps want to borrow it again then.'

NONCOMITTAL RESPONSE

The distribution of these different functions in the Tzeltal data set is shown in Table 5, which summarizes the proportions of different actions performed by polar questions and content questions in the data examined. (The four alternative questions in the data are omitted from the table; they were all functionally information requests.)

The first observation is that, overall, only a bit over a third (38\%) of the coded Tzeltal questions were used to request information (in the sense of asking the addressee to supply information that the questioner does not have). This is largely due to the prominence of polar questions, which overwhelmingly are used to request confirmation. 
Table 5

Actions performed by different question types.

\begin{tabular}{lcc}
\hline & Frequency: polar questions & Frequency: WH-questions \\
\hline Request new information & $76(33 \%)$ & $39(52 \%)$ \\
Request confirmation & $132(58 \%)$ & $1(1 \%)$ \\
Initiate repair & $4(2 \%)$ & $30(40 \%)$ \\
Assessment/opinion + request for agreement & $7(3 \%)$ & $1(1 \%)$ \\
Other & $10(5 \%)$ & $4(5 \%)$ \\
Total & 229 & $75(45 \%)$ \\
\hline
\end{tabular}

This finding is interpretable only in the light of a characteristic of the Tzeltal response system: Tzeltal speakers conventionally repeat, rather than simply saying 'yes'/‘no', or supplying a minimal response (like 'hm') to an utterance offering new information (Brown, 1998; Brown and Levinson, 2005). These repeats are full turns in their own right, not just continuers (floor-passers). Since these second-position repeats are often marked with question intonation, tags, and/or dubitative particles, they were often coded as questions and assessed as 'confirmation requests', even when the information at issue had just been mentioned. My analysis is that Tzeltal speakers routinely request confirmation of new information just supplied, not necessarily because they didn't hear or don't believe it but simply to firmly establish it in common ground before proceeding with the topic. This conversational convention for managing feedback of course elevates the number of questions categorized as 'confirmation requests'.

Another Tzeltal convention perhaps explains the very low proportion of 'assessments' done with interrogative and other potential-question forms. Because a conventional way to express an attitude and prompt for agreement is with a rhetorical question - recall that these are not functionally questions and therefore were not included in our counts - the rhetorical question form perhaps pre-empts the use of genuine questions to proffer assessments/opinions.

Does the form of marking of Tzeltal polar questions interact with their likelihood of being used as genuine information questions? Table 6 shows the distribution of actions across the three main types of polar question marking (the dedicated interrogative marker bal vs. tag bi vs. rising intonation) and non-marked declarative questions. (As these categories are not mutually exclusive, percentages are not given.) It is clear from the table that tags are not used as repair initiators; they are mostly used to request confirmation, although a substantial number of tag questions (10) do request new information. The division of labor with bal is the opposite: more than half are used in genuine information questions, and only a quarter in confirmation requests.

Our third type of question, alternative questions (of which there were only four in the data), perform actions differently: they switch the action en route and proffer a candidate answer, as in:

$<28>\quad$ [chanit 15:32:, A is being asked about where his American ex-wife summoned him to court]

C: ^yu'un naxjich tey la to 'w-ich'-0 ik'-ula-el $a^{\prime} k$ - $a^{\prime} y$

because PT thus there CMP still 2E-receive-3A fetch-CNT-NOM CMP 1E-hear

'Because was it as I heard that you got summoned there

ta (1.0) me ta jobel ba jejch-uk a $a^{\prime} \quad k-a^{\prime} y \quad$ tz'i la

PREP if PREP San.Cristobal where side-SUBJ CMP 1E-hear PT CMP

to, if (it was) to San Cristobal wherever I gather that

$y$-ik'-ula-at=e, mak k'alal ta s-lum-al bit'il la k-a'y tz'i.

3E-summon-CNT-2E=CLI PT as.far.as PREP 3E-land-NOM how CMP 1E-hear PT

she summoned you, (or) perhaps all the way off in her own land or however I heard it.'

[i.e., which was it, in S.C. or in the USA?]

A: jo'uli ta jobel $i$.

no here PREP San.Cristobal DEIC

'No, here in San Cristobal.' [denies the second part of the double question and affirms the first part]

In short, it appears that actions performed by Tzeltal questions are specialized by form to some extent, with tag bi and dubitative markers heavily used for confirmation requests in contrast to bal and WH forms, as well as alternative and multiquestions, which are much more likely to be used to solicit information.

\section{Patterns of fittedness between questions and their responses}

In the extensive conversation analytic literature based on work on English talk-in-interaction, Q-A sequences are the canonical type of adjacency pair: a question creates a sequential context where an answer is expected, and makes the addressee accountable if an answer is not forthcoming (Schegloff and Sacks, 1973). If the same holds in other languages, then 
Table 6

Actions of differently marked types of polar questions.

\begin{tabular}{|c|c|c|c|c|}
\hline & $\begin{array}{l}\text { Polar questions } \\
\text { marked with bal }\end{array}$ & $\begin{array}{l}\text { Tag questions } \\
\text { with } b i\end{array}$ & $\begin{array}{l}\text { Questions marked } \\
\text { with intonation only }\end{array}$ & $\begin{array}{l}\text { Unmarked } \\
\text { declarative questions }\end{array}$ \\
\hline Information request & 20 & 10 & 18 & 28 \\
\hline Confirmation request & 9 & 35 & 27 & 61 \\
\hline Repair initiator & 1 & 0 & 3 & 0 \\
\hline Assessment & 2 & 5 & 0 & 0 \\
\hline Other & 2 & 3 & 2 & 3 \\
\hline Total & $34(15 \%)$ & $53(23 \%)$ & $50(22 \%)$ & 93 (40\%) \\
\hline
\end{tabular}

in Tzeltal we might expect to find the same preferences for responding with an answer and for 'fittedness' between the form of a question and its response, so that, for example, a positively phrased polar question expects an affirmative answer and a negatively phrased question expects a disconfirmation.

\subsection{Tzeltal interactional style}

The patterns of responses to questions need to be considered in light of certain characteristics of conversational style in Tzeltal (see Brown, 1998; Brown and Levinson, 2005; Rossano et al., 2009). The first is a dyadic tendency - the tendency for conversations to be predominantly two-party, with a single addressee expected to respond frequently, at each TCU boundary, resulting in an absence of very long extended multi-TCU turns. The second is next-turn (or 'dialogic) repetition, a response pattern - well-known in Mayan languages - that favors repeats or partial repeats of the prior utterance as tokens of understanding in response to new information. A third is avoidance of mutual gaze, which characterizes many relationships and limits the role gaze plays in signalling communicative intentions (Rossano et al., 2009; Brown and Levinson, 2005).

These features of Tzeltal conversational style mean that procedures for selecting a next speaker are not well-illustrated in the current data set. Although a next speaker is clearly selected $98 \%$ of the time, this is an artifact of the fact that those conversations are predominantly dyadic even when there are more than two participants present. The precise way a next speaker is selected is also underspecified in this data. In Tzeltal, names are not much used in address, and kinship terms are the default address forms (Brown, 2007), but in these data they are used rarely (in only 5\% of the questions). Nor is nextspeaker selection done primarily by gaze (mutual gaze is very restricted in this speech community). Suppression of gaze is also is reflected in the complete absence of visible-only (nods, head-shakes etc.) responses to questions.

Armed with this sketch of interactional style, we may now ask: how do Tzeltal speakers respond to questions?

\subsection{Responses to questions}

\subsubsection{Response types}

Does the response (when it occurs) supply an answer? The data presented in Table 7 shows that, yes, generally (74\% of the time) it does.

In the $7 \%$ of cases when there is no response to a question, is the absence explicable? Some cases are explainable by virtue of the fact that the questioner has no rights to the floor (e.g., a child), or the addressee displays polite hesitation (e.g., to respond positively to an offer of a meal) and has to be repeatedly urged, or because the question is addressed to oneself. Other instances of non-response occur when the speaker produces a 'through-produced multi-question', failing to pause for an answer before producing a second clause, and the answer, when it comes, attends only to the expansion of the question.

In contrast, $19 \%$ of questions did receive a response in the next turn but the responses were not actually answers to the question. Various kinds of situations pre-empt an answer in the immediate sequential context of a question. One is lack of knowledge; the addressee 'doesn't know' the answer. Another is repair initiation, in which case the answer response is held in abeyance while some trouble is dealt with, but (usually) the question eventually gets answered (see $<5>$ above). A third is when the response allows an answer to be inferred (see A's first response in $<6>$ ). Overwhelmingly, Tzeltal questions are treated as expecting an answer in the next turn, and an answer is in fact usually supplied.

\subsubsection{Response types and their distribution}

As we have seen, content questions in our data set, unless they are repair initiators, tend to be IQs; their answers tend to supply the missing information. There is a much wider range of possibilities for the form of the response to polar questions. In conversation analytic work on English, it has been observed that there are two preferences relevant to polar questions: (1) an action type preference favoring a pro-social response (agreeing, confirming, accepting the terms of the question) (see Heritage, 1984; Pomerantz, 1984) and (2) a preference concerning the form of the response, which in English for polar questions is 'yes' (to positively phrased questions) or 'no' (to negatively phrased questions) (see Raymond, 2003). You can therefore get cross-cutting preferences (Schegloff, 2007), when the action type preference prefers a complying response but its polarity prefers a different kind of response (e.g., 'no'). These preferences are consequential for how the sequence unfolds. 
Table 7

Responses to Tzeltal questions.

\begin{tabular}{lcr}
\hline Response type & Frequency & $\%$ \\
\hline Answer & 229 & 74 \\
Non-answer response & 58 & 19 \\
No response & 21 & 7 \\
Total & 308 & 100 \\
\hline
\end{tabular}

A repeat rather than a 'yes' or 'no' answer to a polar question in English implies something additional-for example a challenge to the question as formulated (Raymond, 2003), or an indication that the repeater has made a prior allusion to the information expressed in the repeat (Schegloff, 1996). Type-conforming answers to polar questions are (in English) 'yes' or 'no'; these are the 'preferred' response forms, unmarked (not carrying additional implications) and more frequent than nontype-conforming responses.

In Tzeltal, however, repeats are the most frequent form for positive (affirming) responses to polar questions; in many contexts they are the default form for a minimal affirmative response. Children of age 2 already show sensitivity to this default, and they may be corrected if they answer just jm 'hm' or yak 'yes' to such questions (Brown, 1998).

This repeat-as-affirmation response type is exemplified in many of the examples presented above (e.g., examples 8,12 , $13,15,20,25)$. It is not peculiar to Tzeltal; many other languages have 'echo response systems' (König and Siemund, 2007: 320-21), with repeats as the normal way to affirmatively answer polar questions (see Brown et al., 2009, for some other Mesoamerican languages; Jones, 1999 for Welsh; Keevallik, in press for Estonian; Hakulinen, 2001 and Sorjonen, 1996, 2001a,b, for Finnish).

The form of answers to all polar questions in the Tzeltal data is summarized in Table 8, which clearly shows the tendency to answer a polar question with a repeat if responding affirmatively: $62 \%$ of affirmative answers to questions were repeats, while only $34 \%$ were 'yes'-'no' or other interjection non-repeat forms. Among the languages compared in this project, Japanese is similar, if less extreme in this regard (see Hayashi, this volume). In order to understand these non-repeat answer forms, we need to look in some detail at the range of options for answering a polar question and the division of labor among them.

There is actually a large repertoire of yes/no response types, including repeats of various sorts ( $l a, j a$ ', $a y$, etc.), response words or interjections like $y a k$ 'yes', ju'uk 'no', ja'bi ('yeah', 'that's right') and jm ('hm'). ${ }^{9}$ The principle ones are presented in Table 9, along with a roughly corresponding English response type as a gloss. Given this repertoire of 'yes'/'no'-type responses, it is clear that Tzeltal, like Finnish (Sorjonen, 2001a,b) and Estonian (Keevallik, in press), has a mixed system with both echo repeats and interjections as dedicated answer forms.

A visible component to the response may accompany, but not supplant, these overt response forms. In fact visible components (e.g., nods, head shakes) were a part of only $21 \%$ of responses to questions, and were never the sole component of a response.

Note that with the exception of yak 'yes' and ju'uk 'no', none of these forms is restricted to the sequential context of responding to questions, although they are generally responsive forms. Note also that going down the columns - from repeats to response words to interjections - they have decreasing semantic content, prompting one to wonder whether there might be something analogous to the scale of minimality suggested for Finnish (Hakulinen, 2001) constraining their applicability in different contexts:

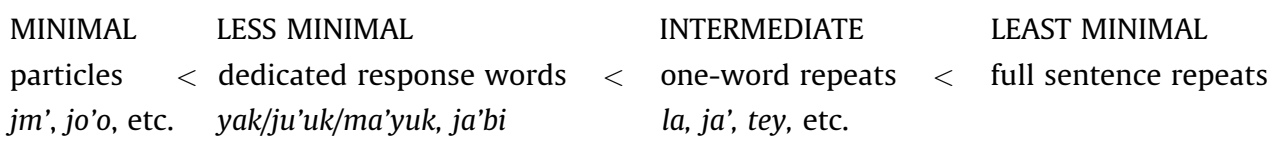

Examples of each of these response types follow.

4.2.2.1. Answering with a repeat: [repeated parts are underlined]. Repeats can be either a full clause or a partial repeat focussed on a particular element in the question, always adjusting deictic elements and evidentials to maintain the proposition being repeated. A full sentence repeat is a semantically complete proposition and often does something 'more' than simply answering the question:

\footnotetext{
${ }^{9}$ See Schegloff, 1981 for usage of some such response forms in English. The corresponding Tzeltal ones are underanalysed here; this is a topic for further research. Note that we label these 'interjections' as a neutral cover term for non-repeat response forms including words like 'yes' and 'no', 'right', 'okay', 'thus', and non-words like jm, uhhuh, and uh'uh'.
} 
Table 8

Form of the answer to polar questions.

\begin{tabular}{lrr}
\hline & Affirming & Disaffirming \\
\hline Repeat & 95 & 5 \\
'Yes'- or 'no'-word or interjection & 53 & 17 \\
Other & 6 & 3 \\
& $154(86 \%)$ & $25(14 \%)$ \\
\hline
\end{tabular}

Table 9

Response types to polar questions.

\begin{tabular}{|c|c|c|c|}
\hline Affirm positively phrased question & $\begin{array}{l}\text { Affirm negatively phrased } \\
\text { question }\end{array}$ & $\begin{array}{l}\text { Disconfirm positively } \\
\text { phrased question }\end{array}$ & $\begin{array}{l}\text { Disconfirm negatively } \\
\text { phrased question }\end{array}$ \\
\hline \multicolumn{4}{|l|}{ Repeats } \\
\hline Full-sentence repeat "P” & $\begin{array}{l}\text { full-sentence repeat “Not P”' } \\
\text { (e.g., Q: 'Did he not come?' } \\
\text { A: 'He didn't come.') }\end{array}$ & & Assert the positive ("P”) \\
\hline $\begin{array}{l}\text { Minimal repeat (of verb or } \\
\text { other focal element) } \\
j a \text { ' 'it's the case' } \\
\text { la '(it) did' } \\
\text { tey 'there' }\end{array}$ & ma'yuk 'none, nothing, not at all' & $\begin{array}{l}\text { ma'yuk 'none, } \\
\text { nothing, not at all' }\end{array}$ & \\
\hline \multicolumn{4}{|l|}{ Interjections } \\
\hline $\begin{array}{l}\text { yak 'yes' } \\
\text { ja'bi 'that's it' } \\
\text { jich 'thus (it is)' }\end{array}$ & ju'uk 'no' & ju’uk 'no' & \\
\hline jm' 'hm' & & jm'm 'uh'uh' & \\
\hline $\begin{array}{l}\text { jo' ‘yeah' } \\
\text { jo'o 'uh-huh' }\end{array}$ & & jo'u & \\
\hline
\end{tabular}

[T030007 chelap 2:49:, $\mathrm{X}$ is asking about C's crops]

$\mathrm{X}$ : ^ ${ }^{\wedge} m a^{\prime} y u k$ to ba ay-0 $\quad$ [te'ye.

NEG-SUBJ still where EXIST-3A PT

'There's none there yet [young corn].'

C: $\quad\left[m a^{\prime} y u k\right.$ to ba ay-0 ajan.

NEG-SUBJ still where EXIST-3A young.corn

'There's no young corn yet.'

(See also $<14,25>$ above, and see $<13,23>$ showing how in full-sentence repeats the 'shifters' (person deixis, evidentials) adjust to keep the proposition the same.)

Verb-alone (or other focused element alone) repeats provide relatively 'minimal' responses-doing nothing beyond the confirming response. Keevallik's (in press) analysis for Estonian seems applicable to Tzeltal as well: a verb-repeat or other one-word repeat "is a minimal answer to questions that are not formatted to imply too much problematicity or social sensitiveness." This tendency to answer with a verb or other focal word alone as a minimal repeat is illustrated in many examples above (e.g., 8, 10, 12, 20). The repeat is of whatever element in the question utterance is queried, as in:

$<30>\quad$ [T002010 chanit 7:59:, talking about government money granted to the community]

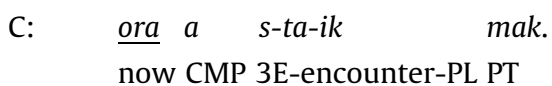

'Right away they found it perhaps.'

(0.2)

A: $\quad$ ora-

'Right away.'

Affirmative repeats can prompt long sequences-response cycles (Brown and Levinson, 2005) of reiterated repeats, very characteristic of Tzeltal conversations. Ex. $<31>$ illustrates this, as well as the fact that not all repeating utterances are 
answers to questions-repetition is a general resource for responding affirmatively or agreeing with a claim in the preceding utterance. $^{10}$

$<31>\quad$ [T013040 nail53 34:05:; A is demurring from accepting offer of a corn gruel drink]
A: $\quad j a^{\prime} \operatorname{nax} m a \quad s-k^{\prime} a n \quad x-y-u c h^{\prime}-0 \quad i \quad k-a^{\prime} a l-t i k \quad i$.
! PT NEG 3E-want ASP-3E-drink-3A this 1E-water-1PLE DEIC
'It's just that she doesn't drink our water.'
$\mathrm{N}$ : aj pero pay-bil me ye'l ek tz'i ja'ya k-uch'-tik.
ah but boil-RES if apparently too PT ! ICP 1E-drink-1PLE
'Ah but it's the case that we too drink it boiled.' [i.e., it's safe to drink]
A: $\quad$ aj pay-bil ya 'w-uch'-0 ek
CONFIRMATION CHECK 1
ah boil-RES ICP 2E-drink-3A too
'Ah you drink it boiled too.'
$\mathrm{N}$ : pay[bil -
CONFIRMATION
boil-RES
'Boiled.'
A: $\quad[$ pay-bil?
CONFIRMATION CHECK 2
$(.2)$

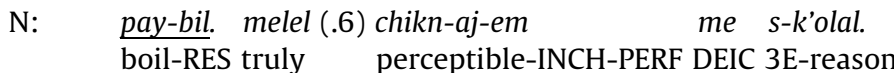
'Boiled. Truly, (we've) heard about the reasons (for boiling drinking water).'

Aside from a repeat of (part of) the question, there are two more general resources for uttering a minimal answer as a repeat. The completive aspect particle $l a$, in all other contexts a bound morpheme that cannot occur alone, functions alone as a repeat, affirming that the event predicated in the question did indeed occur:

$<32>\quad$ [T002015 chanit 11:02:; talking about government visitors being given gifts, including special Tenejapan clothes]

C: $\quad \underline{\text { la }} \quad y$-ich $s-k^{\prime} u^{\prime} \quad y$-u'un-ik $e k^{\prime} t z^{\prime} i n$.

CMP 3E-get 3E-clothes 3E-RELN-PL too PT

'They got their own (Tenejapan) clothes too then?

A: $\quad \underline{\text { la }}$.

CMP

'(They) did.'

And sentences in any aspect formulated with the proposition-affirming particle $j a$ ' ('it is the case that') can be affirmed by repeating the $j a$ :

$<33>\quad$ [T037012 xpetslus 3:28:, P, a visitor, has been telling L about her (P's) elder sister's sore legs]

L: $\quad j a^{\prime}$ jich ya $x$-ben-0 a me y-ala te'-el.=

! thus ICP ASP-walk-3A there DEIC 3E-DIM stick-NOM

'It's that thus [that's why] she walks with [the help of] her little stick.'

P: $\quad=\underline{j a:}$.

!

'It's that.'

(Actually, ja' can sometimes function as an interjection rather than a repeat, affirming a prior utterance that has no explicit $j a$ ' in it.)

\footnotetext{
${ }^{10}$ In Finnish (Sorjonen, 2001a,b), repeat responses tend to offer affirmation of a question that is asking for information, and the action which the question introduces or continues is generally continued on after the repeat; yes/no particle answers tend to be more finalizing. In Tzeltal, in contrast, repeats are more broadly used in responses, as answers to confirmation requests as well as to genuine information requests.
} 
Recall that the 'repeat' may be partial, indeed as in $<32>$ and $<33>$ quite minimal, and will always switch deictically and evidentially to take account of the change of speaker; hence tey 'there' is always the affirming repeat version of a question about li' 'here', as in $<34>$ :

$<34>\quad$ T006004 xunsen 41:52:

MS: $\quad \underline{i}^{\prime}$ to wan ta pat k'inal tz'i ba-em-0 a? here PT PT PREP back land PT go-PERF-3A DEIC '(It's) here to the back of the mountain she's gone?'

$\mathrm{x}: \quad$ te:y.

there

'(It's) there.'

In all these examples $<30-34>$, it would be ill-formed (non-conventional, susceptible to correction) to respond with yak 'yes'.

4.2.2.2. Answering with yak 'yes'. The use of the affirmative word yak as an answer to a polar question is quite restricted: $y a k$ is used to affirm actions and mental states of the speaker himself, his own plans, actions or belongings or those of others for whom he has firsthand knowledge. Yak was the answer form for just 13 questions in the dataset.

$<35>\quad$ [T013001 nail 25:37:, A is visiting N, who is a ritual specialist in the local religious hierarchy]
A: ju'uk, ya $x($.$) mo-at=ix ta lum tz'ita merkolextik=e?$
no ICP ASP ascend-2A=ACS PREP town PT PREP Wednesday=CLI
'No, you will go up to town then on Wednesday?'
$\mathrm{N}$ : $\quad y a k$ cha'wej=e.
yes day.after.tomorrow=CLI
'Yes, the day after tomorrow.'
$<36>\quad$ [T037035 xpetslus 10:46:; final acceptance of offer of a meal]
L: $\quad y a x^{\prime}$-och-ex tal $i \quad b i \quad k$-antzil.
ICP ASP-enter-2A DIRcome DEIC TAG 1E-daughter
'You-plural are coming inside are you, my girl.'
(0.4)
Xp: $\quad y a k$.
'Yes'.

Unlike English yes and Finnish joo, yak never immediately follows a repeat answer by the same speaker in the Tzeltal data.

A related agreement word with the subjunctive suffix -uk is yakuk, best translated as 'okay'; in response to questions yakuk is used only for agreeing to do something.

$<37>\quad$ [T012018 bot50 12:15:; request for a curing ritual]
A: $\quad y a$ bal $x^{\prime}-o^{\prime}$ bolba $\quad a^{\prime}$-pas-0?
ICP Q ASP-take.pity.on 2E-do-3A
'Will you please do it?'
B: yakuk.
'Okay.'

By saying yakuk, B commits to performing the requested ritual.

4.2.2.3. $j a$ 'bi. The word $j a$ 'bi is a conventional form for an affirmative response (roughly equivalent to English 'yeah' or 'that's right' as affirmation); it provides stronger affirmation than the more minimal jm, and occurred 7 times in the data:

$<38>\quad$ [chanit T002008 7:16:]
A: ora la s-ta-0
kolta-el s-tukel y-il-el (.) ay-0 (.9)
now CMP 3E-encounter-3A help-NOM 3E-self 3E-see-NOM EXIST-3A 


\author{
ay-0 s-tzob-oj s-ba antz-etik mach'a ya (.) \\ EXIST-3A 3E-gather-PERF 3E-REFL women-PL who ICP \\ jalojom-etik ay-0. \\ weaver-PL EXIST-3A \\ 'Right away they got help it seems [i.e., government aid], the women who are weavers gathered \\ together.' [to ask for aid] \\ C: $\quad$ aj $j a^{\prime} t z^{\prime} i$ socio-etik $e k^{\prime}[=e$. \\ ah! PT society-PL too=CLI \\ 'Ah it's their 'socio' [weavers' club].' [inference: this is what you are referring to] \\ A: \\ [ja'bi. \\ 'That's it.' \\ C: $\quad j a^{\prime}$ kati. \\ ! PT \\ 'It is!'
}

4.2.2. jich. The adverb jich 'thus, (it was) like that' when used as an answer indicates that the prior turn characterized the situation correctly:

<39> [T013026 nail53 30:38:; after being told by N about N's kinsman who went to inspect and measure land, first to Xixintonil and then to Chulja', A offers a calculation]

A: $\quad c h a^{\prime}$-pam to ya $y$-il-0.

two-CL still ICP 3E-see-3A

'Two plots he (went to) see.' INFERENCE

$\mathrm{N}$ : jich.

'Thus.' [=that's right'] CONFIRMATION

$Y a k, j a$ 'bi,ja' and jich are all confirming words, each with a somewhat different fit to the form and/or semantics of the prior discourse. As an initial attempt at characterizing the division of labor between them, I suggest that yak, as mentioned, affirms the speaker's own personal intentions, feelings, or experiences. In contrast, ja'bi can provide a more general affirmation based on speaker knowledge ('that's right') or it may be a mere floor-passer. Ja' as a response form depends on the form of the question, which usually has been formulated with ja' (i.e., ja' is a minimal repeat, or at least implicit in the question), and jich is appropriate in the context of a prior utterance formulated as the expression of an event ('thus, it was like that').

4.2.2.5. Response tokens. Response tokens like jm, joo, jo', jo'o, etc. have no semantic content but are inherently responsive; like ja'bi, they can be used to affirm something the speaker knows or to just pass the floor. In Tzeltal they are not normally used to provide initial answers to a question, but there are a few cases in the data, for example $<40>$, which illustrates the fact that joo alone may well be treated as insufficient as an answer and be pursued for confirmation:

$<40>\quad$ [T013052 nail53 40:06:; $\mathrm{N}$ is explaining to his visitor A how deep in a local cave goes]

$\mathrm{N}$ : ay-0 najt nax nix tz'in pero (.) chikan-0 ja' nax jich s-najt-il

EXIST-3A long/far PT PT PT but visible-3A ! PT thus 3E-long-NOM

bel ochel bel ja'chuk(0.9) in s-najt-il.

DIRgo DIRenter DIRgo like.that this 3E-long-NOM

'It's far/deep then, but it's apparent, its distance is just like this.' [gesturing to show how far in the cave goes]

A: $\quad$ xujk na.

CONFIRMATION CHECK

corner house

'(to the) corner of the house' [gestures to house corner as a candidate distance measure]

$->\mathrm{N}: \quad$ joo. $[$ nods]

'Yeah'

A: $\quad \underline{j}$ nax jich mene. $=$

PURSUIT OF CONFIRMATION

! PT thus that 

'It's just like that' [i.e., that distance]
$\mathrm{N}: \quad=\underline{j a^{\prime}}$.
CONFIRMATION
'It is.'

Like in Finnish (Hakulinen, 2001; Sorjonen, 2001b), these forms are more likely to be confirming responses to something inferred, rather than to an initial topic-introducing question.

4.2.2.6. ju'uk, ma'yuk. To affirm a negatively phrased question, the words ju'uk 'no' and ma'yuk 'none, nothing' are the most frequent choice, as in $<41>$ and $<42>$ (or repetition of the negative particle, as in $<9>$ above).

$<41>\quad$ [T013032 nail53 32:23:; A has asked what time of day N got home from his trip to visit a kinswoman yesterday, $\mathrm{N}$ has just replied 'same time as now', i.e., mid-afternoon, from which $\mathrm{A}$ infers the distance]

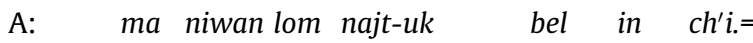
NEG PT very long/far-SUBJ DIRgo DEIC PT
'It perhaps isn't very far then?' [where the kinswoman lives]
$\mathrm{N}$ : $\quad=j u^{\prime} u k$.
'No.' [i.e., it's not far]
A: ju'uk.
$\mathrm{N}: \quad j u ' u k . \quad$ CONFIRMATION
'No.'

The word ma'yuk in answers is often a kind of repeat, matching the negative in the proposition of the question, as in $<42>$ (it would be ill-formed to use ju'uk here; see also <44>).

$<42>\quad$ [T028008 anttzuj 3:25:, T has been telling his visitor X about a woman who stole crops from T's cornfield]
$\mathrm{X}: \quad \underline{m a}$ s-jun-ej-uk $s-b a \quad[i n=e$.
NEG 3E-accompany_PERF-SUBJ 3E-REFL DEIC = CLI
'Those other ones didn't accompany her [in her raid]?'
T: [ma'yuk.
CONFIRMING ANSWER
none/nothing (lit.: NEG-EXIST-SUBJ)
'No (none of them).'

Ju'uk and ma'yuk are also the terms of choice to disaffirm, provide a negative answer to a positively phrased question:

$<43>$

[T035010xunxti7A 3:19:, Two sisters visiting, talking about crops]

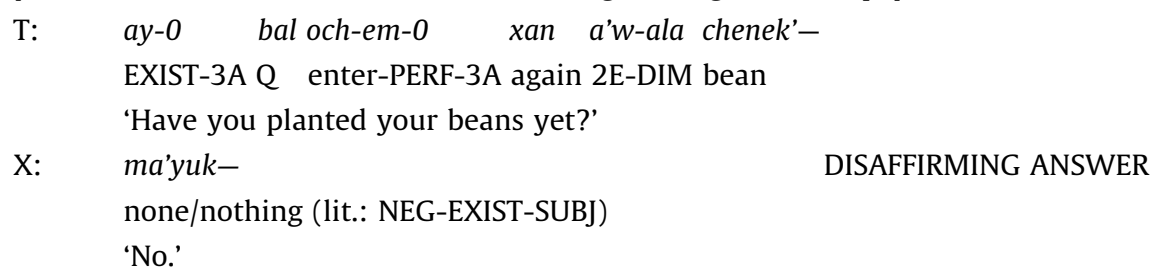

They are differentiated by the semantics and form of the question that they can be responses to: ju'uk is a general disaffirming word ('no'), ma'yuk responds to questions formulated with or implying an existence predicate (does X exist', 'is there any X'? etc.) Both can stand alone as a response to a question or can be continued with a fuller repetition (see $<29>$ above).

\subsubsection{Type conformity}

In Tzeltal, just as in English (Raymond, 2003), information-seeking utterances can be structurally designed to prompt for a 'yes' answer (e.g., 'Are you going?' or 'You're going, are you?'), or a 'no' answer: ('You're not going?'). Now we are in a position to ask further: Is there a corresponding preference in Tzeltal for answers to confirm the presumptions conveyed by the form of the $\mathrm{Y} / \mathrm{N}$ question? Regardless of how the question is formulated, is there evidence for a structural preference for agreement, for questions to be 'aligned with'? Table 8 showed that disconfirmation happens only in $16 \%$ of cases in the data, 
indicating that Tzeltal is indeed in conformity with the preference for affirmation established in the study of responses to questions in other languages.

Furthermore, when responses do disconfirm, there is evidence that this is a dispreferred action: disconfirming answers tend to be delayed, pursued for re-confirmation (as in $<44>$; see also $<16>$ above), or have an account or expansion tacked on (Heritage, 1984), as in $<45>$.

$<44>\quad$ [T013021 30:14: nail53; winding down the conversation]

A: eej lek me ay-0 in ch'i j-tatik- ay-0 to bal ba

eh good if EXIST-3A DEIC PT HON-'sir' EXIST-3A still Q where

ya $x$-ala ba-at ya'tik tz'in?

ICP ASP-DIM go-2A today PT

'Eh it's good if that's the case, 'sir', is there somewhere you are going to go now?'

$\mathrm{N}: \quad$ ma'yuk-

DISCONFIRMING ANSWER

'No(where)'

A: ma'yuk-ix a [tz'in.

PURSUIT OF RECONFIRMATION

none $=$ ACS DEIC PT

'There's no(where) then.'

$\mathrm{N}:$

[ma'yuk.

CONFIRMATION

'No(where).'

$<45>\quad$ [T019019 pak'elv7 14:14:; talking about A's land]

P: $\quad$ ja'at (to ix) $\quad a^{\prime} w$-ich'-oj.

you (still ACS) 2E-receive-PERF

'You (ve still) got it [your land in 'hot country'].'

A: $\quad j u^{\prime} u k, s-m a k-o j-i k \quad y a^{\prime} t i k$.

DISCONFIRMATION + EXPLANATION

no 3E-block-PERF-PL now

'No, they've taken it away (from me) now.'

Another possibility is an answer phrased without any 'yes'/'no' response word or interjection, but one that makes a disconfirming answer clear and corrects the mistaken claim or presumption:

$<46>\quad$ [T002038 chanit 17:32:]

C: $\quad l i^{\prime} \quad$ bal ay-at ta $a^{\prime}$-na li $\quad$ ta (.) $a^{\prime} w$-ala $k^{\prime}$ inal-ik $t z^{\prime}$ in i?

here Q EXIST-2A PREP 2E-house here PREP 2E-DIM land-PL PT DEIC

'Your house is here, here on your land then?

(.6)

$j u^{\prime}[u k$ mak.

no PT

'Maybe not.'

A: [te: lum to ay-on ta ba ay-0 s-tz'eel eskwela.

DET there still EXIST-1A PREP where EXIST-3A 3E-side school

'There, I'm over there by the side of the school.'

Because $j u$ ' $u k$ 'no' is used to respond affirmatively to a negatively phrased question, $j u$ 'uk is not usually usable to disconfirm one. Characteristically, the disconfirming response just asserts the positive, without overtly saying 'no that's wrong', as in:

$<47>\quad$ [T013054 nail53 40:12:; talking about local caves. $\mathrm{N}$ is the expert]

A: $\quad m a^{\prime} y u k$ ba ay-0 lom t'ujbil-0.

NEG-SUBJ where EXIST-3A very beautiful-3A

'There's no one [cave] very beautiful?' 
$\mathrm{N}: \quad t^{\prime}$ ujbil-0 nix, t'ujbil-0 nix $t z^{\prime} i$ ma.

beautiful-3A PT beautiful-3A PT PT PT

'(There are) beautiful ones, (there are) perhaps beautiful ones.'

To sum up: repeat confirmation responses are in most contexts the 'type-conforming' default in Tzeltal: they accept the terms of the question and allow the sequence to progress with the least amount of detouring. We are now in a better position to understand the form of non-repeat ('interjection') answers shown in Table 8 . Of these non-repeat answers, $14 \%$ were disconfirming. The rest overwhelmingly occurred in one of a set of specific action contexts, where other answer types are appropriate. The word yak 'yes' is highly restricted functionally, and the word ju'uk 'no' is used to affirmatively answer negatively phrased questions (except those formulated with ma'yuk) or to disconfirm positively phrased ones.

\section{Conclusions}

Tzeltal question-answer sequences display certain properties which bring into question the generality of some findings based on English conversation: in particular, (i) the minimal use of visible signals (head nods or shakes) as well as minimal deployment of gaze in next-speaker selection, (ii) repeats as the default form of confirming answers, and (iii) a functional emphasis on confirmation requests rather than on information seeking (a characteristic of the feedback system). Tzeltal questions and answers suggest some interesting issues to be pursued more deeply in Tzeltal and also in cross-linguistic studies of action types in relation to linguistic form in interaction:

1. Different forms of marking are associated with different functions (e.g., bal for information polar questions, bi for confirmation requests). Is this generally true across languages?

2. There seems to be a scale of minimality (Hakulinen, 2001) that partially accounts for differential usage of the different response form types. This idea is worth pursuing, as the basis for a fuller typology of response types and the action implications of different degrees of minimality in their expression.

3. There is good evidence for repeats as part of the response system in Tzeltal (Brown and Levinson, 2005; Rossano et al., 2009), not just as the type-conforming response to polar questions. How frequent across languages is this association between repeats as responses to polar questions and repeats as more generally forming part of the default response system to non-question utterances, as a generic way to agree with a prior utterance?

4. Heavy reliance is placed on tags, dubitatives, and intonation to mark functional questions, showing that expression of doubt about a proposition is ample justification (in the right context of respective presumed knowledge states) to treat an utterance as a question warranting an answer. This is doubtless true of other languages as well, to varying degrees. Are there typological generalizations to be made concerning the respective importance of these different forms of marking in different languages?

In addition, Tzeltal provides evidence for universal tendencies (or at least not limited to English and other European languages) in the ways in which speakers of different languages, in radically different cultural contexts, seek and provide information in conversation. The data presented here provide support for a view of question-answer sequences as archetypal adjacency pairs with a strong propensity for questions to be immediately followed by answers, and in the case of polar questions, for type-conforming answers. In this respect they support the view of preference structures having a generality that reveals underlying cooperative characteristics of an 'interaction engine' (Levinson, 2006) that is prior to, and independent of, the idiosyncrasies of particular linguistic and cultural times and places.

\section{Acknowledgements}

This research was funded by the Max Planck Institute for Psycholinguistics, Nijmegen, The Netherlands. Parts of the analyses presented here were initially presented at several workshops on questions organized by the MPI comparative project on Multimodal Interaction. I am grateful to the participants in these workshops for many helpful comments. I am especially indebted to Tanya Stivers, who ran the quantitative and comparative analyses, to Federico Rossano who checked my coding of the subset of data for which gaze was coded, and to Ludy Cilissen, who checked the timing of responses to questions. Many of the conversation videotapes were collected in collaboration with Stephen Levinson during joint fieldwork in Tenejapa. Final polishing of the manuscript was done during my tenure as a Fellow at the Wissenschaftskolleg zu Berlin.

\section{References}

Aissen, Judith, 1996. Pied-piping, abstract agreement and functional projection in Tzotzil. Natural Language and Linguistic Theory 14, 447-491.

Bohnemeyer, Jürgen, 2002. The Grammar of Time Reference in Yucatec Maya. LINCOM Europa.

Bricker, Victoria, 1979. WH-questions, relativization, and clefting in Yucatec Maya. In: Martin, L. (Ed.), Papers in Mayan Linguistics. Lucas Brothers, Columbia, MO, pp. 107-136.

Brody, Jill, 2003. “Why was I late? I don't know.” Tojolab'al answers to questions in context. In: Proceedings of the Conference on Indigenous Languages of Latin America I, University of Texas at Austin, pp. 1-12. 
Brown, Penelope, 1995. Politeness strategies and the attribution of intentions: the case of Tzeltal irony. In: Goody, E. (Ed.), Social Intelligence and Interaction. Cambridge University Press, Cambridge, pp. 153-174.

Brown, Penelope, 1998. Conversational structure and language acquisition: the role of repetition in Tzeltal adult and child speech. Journal of Linguistic Anthropology 8 (2), 197-221.

Brown, Penelope, 2007. Principles of person reference in Tzeltal conversation. In: Enfield, N.J., Stivers, T. (Eds.), Person Reference in Interaction: Linguistic, Cultural, and Social Perspectives. Cambridge University Press, Cambridge, pp. 172-202.

Brown, Penelope, LeGuen, Olivier, Sicoli, Mark, 2009.In: Dialogic repetition in Tzeltal, Yucatec, and Zapotec conversation. Paper delivered at the SSILA conference, Berkeley, CA, July.

Brown, Penelope, Levinson, Stephen C., 2005. Comparative response systems. Paper delivered at the American Anthropological Association meetings, Washington, DC, December 2005.

Clark, Herbert H., 1996. Using Language. Cambridge University Press, Cambridge.

Drew, Paul, 1997. 'Open' class repair initiators in response to sequential sources of trouble in conversation. Journal of Pragmatics $28,69-101$.

Enfield, Nick, Brown, Penelope, de Ruiter, Jan-Peter, 2006. Epistemic dimensions of polar questions: declarative questions and tag questions in comparative perspective. Paper delivered at the Workshop on Questions and their Responses, Max Planck Institute for Psycholinguistics, Nijmegen, March. To appear in: de Ruiter, J-P. (Ed.), Questions: Formal, Functional and Interactional Perspectives. Cambridge University Press, Cambridge. Hakulinen, Auli, 2001. Minimal and non-minimal answers to yes-no questions. Pragmatics 11, 1-16.

Heritage, John, 1984. Garfinkel and Ethnomethodology. Polity, Cambridge, England.

Jones, Bob Morris, 1999. The Welsh Answering System. Mouton de Gruyter, Berlin, New York.

Keevallik, Leelo, in press. Minimal answers to yes/no questions in the service of sequence organization. Discourse Studies 12 (3).

König, Ekkehard, Siemund, Peter, 2007. Speech act distinctions in grammar. In: Shopen, T. (Ed.), Language Typology and Syntactic Description, 2nd ed., vol 1: Clause Structure. Cambridge University Press, Cambridge, pp. 276-324.

Koshik, Irene, 2005. Beyond Rhetorical Questions: Assertive Questions in Everyday Interaction. John Benjamins, Amsterdam/Philadelphia.

Labov, William, Fanshel, David, 1977. Therapeutic Discourse: Psychotherapy as Conversation. Academic Press, New York.

Levinson, Stephen C., 2006. On the 'human interaction engine'. In: Enfield, N.J., Levinson, S.C. (Eds.), Roots of Human Sociality. Berg, Oxford, pp. 39-69.

Monod-Bequelin, Aurore, 1997. Parlons Tzeltal: Une language Maya du Mexique. L'Harmattan, Paris.

Pomerantz, Anita, 1984. Agreeing and disagreeing with assessments: some features of preferred/dispreferred turn shapes. In: Atkinson, J.M., Heritage, J. (Eds.), Structures of Social Action: Studies in Conversation Analysis. Cambridge University Press, Cambridge, pp. 57-101.

Raymond, Geoffrey, 2003. Grammar and social organization: yes/no type interrogatives and the structure of responding. American Sociological Review 68, 939-967.

Rossano, Federico, Brown, Penelope, Levinson, Stephen C., 2009. Gaze, questioning, and culture. In: Sidnell, J. (Ed.), Comparative Studies in Conversation Analysis. Cambridge University Press, Cambridge, pp. 187-249.

Schegloff, Emanuel A., 1968. Sequencing in conversational openings. American Anthropologist 70, 1075-1095.

Schegloff, Emanuel A., 1981. Discourse as an interactional achievement: some uses of 'uh huh' and other things that come between sentences. In: Tannen, D. (Ed.), Georgetown University Roundtable on Languages and Linguistics, Analyzing discourse: Text and Talk. Georgetown University Press, Washington, DC.

Schegloff, Emanuel A., 1984. On some questions and ambiguities in conversation. In: Atkinson, J.M., Heritage, J. (Eds.), Structures of Social Action: Studies in Conversation Analysis. Cambridge University Press, Cambridge, pp. 28-53.

Schegloff, Emanuel A., 1996. Confirming allusions: toward an empirical account of action. American Journal of Sociology 104, 161-216.

Schegloff, Emanuel A., 2007. Sequence Organization in Interaction: A Primer in Conversation Analysis. Cambridge University Press, Cambridge.

Schegloff, Emanuel A., Jefferson, Gail, Sacks, Harvey, 1977. The preference for self-correction in the organization of repair in conversation. Language 53, $361-$ 382

Schegloff, Emanuel\#\#A., Sacks, Harvey, 1973. Opening up closings. Semiotica 8, 289-327.

Sorjonen, Marja-Leena, 1996. On repeats and responses in Finnish conversation. In: Ochs, E., Schegloff, E., Thompson, S. (Eds.), Interaction and Grammar. Cambridge University Press, Cambridge, pp. 277-327.

Sorjonen, Marja-Leena, 2001a. Responding in Conversation: A Study of Response Particles in Finnish. John Benjamins, Amsterdam.

Sorjonen, Marja-Leena, 2001b. Simple answers to polar questions: the case of Finnish. In: Selting, M., Couper-Kuhlen, E. (Eds.), Studies in Interactional Linguistics. John Benjamins, Amsterdam, pp. 405-431.

Tonhauser, Judith, 2002. On the syntax and semantics of content questions in Yucatec Maya. In: Castillo, J. (Ed.), Proceedings of the 6th workshop on American Indian Languages (WAIL). Santa Barbara Papers in Linguistics 14, pp. 106-121.

P. Brown is a linguistic anthropologist whose research and publications focus on the relationship between language, culture and cognition, explored through detailed study of language usage in its sociocultural context. She has conducted fieldwork for many years in the Mayan language Tzeltal, focussing on adult conversation, politeness, spatial language and cognition, as well as on child language socialization. More recently, she has embarked on fieldwork in a second location, Rossel Island in Papua New Guinea, studying infant-caregiver interaction in a comparative project. 